\title{
Hot topic: Health and welfare challenges in the marketing of male dairy calves-Findings and consensus of an expert consultation
}

\author{
Devon J. Wilson, ${ }^{1 *} \odot$ Derick Canning, ${ }^{2}$ Terri Giacomazzi, ${ }^{3}$ Kendra Keels, ${ }^{4}$ Reny Lothrop, ${ }^{5}$ David L. Renaud, ${ }^{6} \oplus$ \\ Nicole Sillett, ${ }^{7}$ Dave Taylor, ${ }^{7}$ Henry Van Huigenbos, ${ }^{8}$ Bob Wynands, ${ }^{4}$ Dave Zuest, ${ }^{9}$ and David Fraser ${ }^{1}$ \\ ${ }^{1}$ Animal Welfare Program, Faculty of Land and Food Systems, University of British Columbia, 2357 Main Mall, Vancouver, BC, Canada V6T 1 Z6 \\ ${ }^{2}$ Canning Farm Ltd., 940 Southside Rd., Upper Stewiacke, NS, Canada B0N 2P0 \\ ${ }^{3}$ British Columbia Ministry of Agriculture, 1767 Angus Campbell Road, Abbotsford, BC, Canada V3G 2M3 \\ ${ }^{4}$ Veal Farmers of Ontario/Canadian Veal Association, 12-449 Laird Road, Guelph, ON, Canada N1G 4W1 \\ ${ }^{5}$ Canadian Association of Bovine Veterinarians, 226E Wheeler Street, Saskatoon, SK, Canada S7P 0A9 \\ ${ }^{6}$ Department of Population Medicine, University of Guelph, Guelph ON, Canada N1G 2W1 \\ ${ }^{7}$ Dairy Farmers of Canada, 21 Florence Street, Ottawa, ON, Canada, K2P OW6 \\ ${ }^{8}$ Van Huigenbos Farms, Fort Macleod, AB, Canada, TOL OZO \\ ${ }^{9}$ Canadian Food Inspection Agency (CFIA), 30585B Progressive Way, Abbotsford, BC, Canada V2T 6W3
}

\section{ABSTRACT}

A diverse group of Canadian experts was convened for a focused 2-d discussion on potential health and welfare problems associated with the marketing (i.e., transportation and sale) of male dairy calves. Written notes and audio recording were used to summarize the information provided on transport times and marketing practices. Content analysis was used to develop a consensus statement on concerns, possible solutions, and recommendations to improve male dairy calf marketing. The group noted that calves across all Canadian regions are commonly transported at 3 to $7 \mathrm{~d}$ of age and undergo transport for 12 to $24 \mathrm{~h}$ or longer depending on the location of their dairy farm of origin. Calves in some regions are marketed almost exclusively through auction markets, whereas others have more direct sales. A need was identified for better criteria for calf fitness for transport, maintaining farm biosecurity, reducing the use of antimicrobial therapy in calf production, and improving education for farmers and veterinarians on the importance of neonatal care for male dairy calves before transportation. Experts noted that major changes in male dairy calf marketing will be required to comply with amendments to the federal Health of Animals Regulations (Part XII) on animal transportation; collaborative effort will be needed to safeguard animal health and welfare as this transition is made.

Key words: expert consultation, male dairy calf, transportation, marketing

Received February 27, 2020.

Accepted August 3, 2020.

*Corresponding author: devon.wilson@ubc.ca

\section{HOT TOPIC}

In Canada and the United States, an estimated 4 to 5 million male calves are produced on dairy farms annually, and many are known to be sold to specialist calf or veal producers. The marketing process may include transport at a young age (less than 2 wk; Renaud et al., 2017) and light weight, which is associated with decreased weight gain (Scott et al., 2020) and increased mortality and morbidity (Winder et al., 2016; Renaud et al., 2018a). Sale through auction markets and commingling with calves from other dairy farms are also commonly practiced (Marquou et al., 2019), with the risk that calves may be exposed to harmful pathogens. Furthermore, long-distance transportation of male dairy calves is common because calf-rearing facilities are often concentrated in specific regions; for example, one study in North America documented 2 loads of dairy calves transported 1,350 km (González et al., 2012). Comparable challenges are faced in Europe, where calves may be sold between countries via longdistance transportation with stops at transfer stations (Bernardini et al., 2012). This raises concerns because distance transported has been associated with an increased likelihood of young dairy calves dying during or shortly after transport (Cave et al., 2005).

Scientific evidence suggests that the marketing process for male dairy calves contributes to negative health outcomes. For example, $43 \%$ of male calves had at least one abnormal finding based on a clinical exam by a veterinarian at an auction market, with the most common abnormality being a swollen navel found in $20 \%$ of calves examined (Marquou et al., 2019). Additionally, upon arrival at veal farms, between 35\% (Pempek et al., 2017) and 47\% (Renaud et al., 2018c) of calves were dehydrated based on a skin tent test. Similarly, in 
Europe, where collection centers are used to assemble calves, a recent study found that $70 \%$ of calves were dehydrated (Marcato et al., 2020). In comparison, a 5\% prevalence of navel inflammation was recently reported in heifer calves (Medrano-Galarza et al., 2018), and the farmer-reported prevalence of dehydration in calves in their first 2 wk is reported to be less than $2 \%$ (Wells et al., 1997).

One response to the health challenges related to the sale and transport of young calves has been to develop and implement regulations that may limit calf age, trip duration, and transport conditions. For example, the European Union and New Zealand, respectively, now have minimum ages of 14 and $4 \mathrm{~d}$ for transportation of young calves (European Union, 2005; National Animal Welfare Advisory Committee, 2018). Amendments to Canada's Health of Animals Regulations (Part XII) on animal transportation, which came into effect in February 2020, limit the transportation of unweaned calves to less than $12 \mathrm{~h}$ and prohibit the use of auction markets for calves $8 \mathrm{~d}$ of age or less (Canadian Food Inspection Agency, 2019). Although regulatory changes may help address health and welfare challenges, these represent only one of many possible approaches. Other approaches include the development of local veal or dairy-beef production, as well as incentive programs or contractual agreements on calf care between calf buyers and sellers.

To better understand the health and welfare risks in the marketing of male dairy calves and propose a range of possible solutions, a diverse panel of Canadian experts was convened. The panel was assembled under the auspices of Canada's National Farmed Animal Health and Welfare Council, which aims to "provide collaborative guidance on a cohesive, functional and responsive farmed animal health and welfare system in Canada" (National Farmed Animal Health and Welfare Council, 2019). The objectives were to (1) describe the range of marketing practices for male dairy calves in Canada, (2) identify the animal health and welfare challenges, and (3) make recommendations to safeguard animal health and welfare and the sustainability of the dairy and calf-rearing sectors.

Following the model used by Stojkov et al. (2018) for cull dairy cows, the study used a 2-d "expert consultation" that involved group discussion among experts with diverse knowledge of the subject. Expert consultation was chosen as a suitable method for initial exploration of a complex problem with significant geographic variation. Experts were recruited through purposive sampling to achieve a wide range of expertise covering dairy farming, livestock auctions, calf and veal production, veterinary medicine, regulation, and research. Participants were recruited by contacting national or- ganizations whenever possible, and otherwise through provincial associations. Organizations included Dairy Farmers of Canada (DFC, Ottawa, ON, Canada), Livestock Markets Association of Canada (LMAC), Canadian Veal Association (CVA), Les Producteurs de Bovins du Québec (PBQ, Longueuil, Que, Canada), Veal Farmers of Ontario (VFO, Guelph, ON, Canada), the Canadian Association of Bovine Veterinarians (CABV, Saskatoon, SK, Canada), Canadian Food Inspection Agency (CFIA, Ottawa, ON, Canada), National Farmed Animal Health and Welfare Council (NFAHWC, Elora, ON, Canada), and other contacts of the University of British Columbia (UBC, Vancouver, BC, Canada) Animal Welfare Program. An expert (or "key informant" in the sense of Krueger and Casey, 2000) was defined as a person with direct, current experience working with dairy or veal calves and who was recommended by one of the above-listed organizations. Experts were recruited from across Canada. Of the 20 invited participants, 17 attended the consultation meeting in person and 3 provided comments after the meeting. All major dairy-producing regions in Canada were represented, including the maritime provinces (Nova Scotia, Prince Edward Island, Newfoundland, and Labrador), Québec, Ontario, the prairie provinces (Manitoba, Saskatchewan, Alberta), and British Columbia.

The meeting was convened by the NFAHWC and the UBC Animal Welfare Program; support was received from the BC Ministry of Agriculture through the Canadian Agricultural Partnership. The project was approved by the UBC Behavioral Research Ethics Board (H19-00170). The meeting, which was held on April 30-May 1, 2019, in Vancouver, was chaired by D. Fraser (NFAHWC and UBC) and coordinated by D. Wilson (UBC) and N. Sillett (DFC).

The planned topics of discussion included (1) marketing and transport of male dairy calves in different regions; (2) potential problems of animal health, welfare, and biosecurity; (3) educational materials, regulations, or other tools that show promise for protecting the health and welfare of male dairy calves; (4) effective criteria for assessing when male calves are fit for transport; (5) potential effects of the amendments to the federal Health of Animals Regulations (Part XII) on the marketing of male dairy calves; and (6) recommendations for action by different stakeholders. Through a focused discussion, participants provided information based on their personal knowledge and experience; this was documented throughout the meeting by written notes and an audio recording of the discussion.

After the meeting, the written notes and audio recording were used to analyze the information provided. Information on marketing and transport in different 
regions was summarized. Content analysis was used for the remaining topics by 2 authors (D. Wilson and D. Fraser) to determine key themes for each topic, as described by Stojkov et al. (2018). These themes were then used to develop a consensus statement describing areas of agreement on challenges, possible solutions, and recommended actions. This material was captured in a draft statement, and the validity of emergent themes was ensured by distributing the draft to the group. Participants then provided corrections and editorial suggestions. This process was repeated 3 times until no further modifications were suggested.

\section{Marketing of Male Calves}

Participants reported highly variable practices across the country in the marketing of male dairy calves, with variation between regions plus external influences including season, international trade, and fluctuations in price. Briefly:

(1) Most calves from the western provinces are transported from the dairy farm of origin to calfrearing facilities in southern Alberta (regionally known as "calf growers"), which produce dairybeef, whereas male calves in the eastern part of the country are generally transported to farms in Ontario and Québec that raise milk- or grain-fed veal.

(2) Calves are marketed at a wide range of ages depending on producer preference, location, milk production levels, and availability of market opportunities. Extremes of 1 to $55 \mathrm{~d}$ were reported, but most calves were reported to be moved from the farm of origin at 3 to $7 \mathrm{~d}$ of age, as is consistent with estimates from dairy farms in Ontario (Renaud et al., 2018b).

(3) Some calves are sold directly from dairy farms to calf-rearing facilities, whereas others are transported to an auction and then to a final destination. The marketing and transportation activities vary by region: in Québec, almost all calves are sold through auction; in Alberta, most are sold directly to calf-rearing facilities; and Ontario has a mixture of auctions and direct sales.

(4) The use of transporters ("drovers") who collect calves from multiple dairy farms and transport them either directly to calf-rearing facilities or to auctions was reported in all regions.

(5) In parts of the country, there is an emerging market for preconditioned dairy calves that are vaccinated, weaned, and well established. Some buyers seek those calves specifically and pay a premium for them, although others prefer to receive calves as early as possible to treat them according to their own protocols.

(6) An unknown (but likely small) proportion of calves are either raised on the dairy farm of origin or hobby farms, euthanized at birth, or slaughtered in the category of lightweight calves (up to $80 \mathrm{~kg}$ ).

The duration of transport is also highly variable. In southern Ontario and Québec, where there is a high concentration of both dairy and veal farms, some calves are transported short distances requiring only a few hours. However, when drovers collect calves by visiting multiple dairy farms in succession, the entire trip (from loading the first calf to unloading) can extend $12 \mathrm{~h}$ or more, even with relatively short distances. Calves from British Columbia that are transported from the Fraser Valley to Alberta (across the Rocky Mountains) typically spend 12 to $24 \mathrm{~h}$ on the vehicle. Similar travel times to Alberta can occur for calves from Saskatchewan and Manitoba. Calves from the most western and eastern regions (Vancouver Island, New Brunswick, Prince Edward Island, and Nova Scotia) may travel for up to $48 \mathrm{~h}$, including a rest stop. Rare situations may extend the time that calves are in transit; for example, if calves are held at an interim location for a period of days while a load is assembled.

\section{Potential Animal Health and Welfare Challenges and Solutions}

Participants noted that the marketing of male dairy calves creates risks to animal health and welfare because (1) young calves have limited body reserves to meet the exertion and possible thermal demands of traveling and handling; (2) any stress caused by handling may suppress immunity to disease; (3) commingling of calves from different dairy farms exposes them to new pathogens; and (4) calves do not always receive an appropriate quantity and quality of feed and water while in the transportation continuum.

The condition of male dairy calves when transported also differs by dairy farm of origin, depending partly on whether the calves receive enough colostrum for transfer of passive immunity and whether adequate milk is provided to support normal growth. There are also important differences in the type and cleanliness of housing. On farms with excellent calf management, retaining calves for $10 \mathrm{~d}$ or more before transportation could improve calf vigor and immunity to disease. However, on farms with poor management of colostrum, 
calf nutrition, air quality, and environmental cleanliness, keeping calves for such periods may create negative health effects. Variable management of calves may occur in part because dairy herd veterinarians differ in their level of involvement with calves (Sumner and von Keyserlingk, 2018).

Variation in early calf management is believed to result in different health outcomes at veal and calf-rearing facilities. Some calf-rearing facilities use methods to determine whether calves received adequate colostrum (e.g., serum refractometry) and relay this and other health information back to the farmers who supply them with calves. This information could motivate improved colostrum provision for male dairy calves; in general, however, there are limited means of communicating such information.

The panel noted that animal health benchmarking; that is, collecting comparative data and communicating it back to producers, has been used successfully to motivate change in rearing dairy heifer calves (Atkinson et al., 2017). The panel recommended that benchmarking of male calf health (e.g., by herd veterinarians) plus feedback of information on later morbidity, mortality, and growth rate be explored to motivate improvement.

\section{Fitness for Transport}

Participants noted that male dairy calves at the time of initial transportation range from healthy and vigorous to weak, dull, and dehydrated. One producer organization (PBQ) developed a decision tool that includes umbilical condition, rectal temperature, and age to help dairy farmers decide whether to transport calves. Participants recommended further research to identify and test simple but accurate methods of scoring fitness for transport in young calves.

Calf age is sometimes used as a proxy for fitness; for example, in New Zealand and the European Union, where a minimum age is set for transportation of calves. However, with variable management and environmental conditions on the farm of origin, calf age may not be a strong indicator of fitness for transport. Furthermore, calf age cannot be traced from the dairy farm through the marketing system in Canada and cannot be reliably determined from physiological or physical characteristics. Given this limitation, researchers recently investigated the accuracy of serum gamma glutamyl transferase and BW as predictors of age in young calves (Buczinski et al., 2020) but these measures showed only moderate ability to predict age. Therefore, further work to develop better measures or improve traceability of age through the marketing system would be beneficial.

\section{Transport Vehicles and Biosecurity}

Participants noted that calf buyers and their vehicles entering dairy farms to collect calves could pose a biosecurity risk, acting as a fomite for transmission of pathogens between calf facilities. Some dairy farms have a separate location, removed from the herd, for collecting calves. In other cases, however, the truck enters the farm, often with calves from other farms already loaded. Participants recommended that the dairy industry's proAction Program (the national dairy farm quality assurance program) emphasize the biosecurity risk posed by trucks collecting calves.

\section{Use of Antimicrobials}

Participants noted that if calf health deteriorates after arrival at calf-rearing facilities, some producers respond with significant use of antimicrobials, including Category I antimicrobials (those of very high importance in human medicine). Blanket antimicrobial treatment on arrival also occurs on some calf-rearing farms, and milk replacer containing medication to control coccidiosis may be fed to all calves until weaning. Other antimicrobials may be fed in the milk on an as-needed basis. These practices are contrary to efforts to reduce the use of antimicrobials and eliminate the use of Category I antimicrobials in animal production (Lava et al., 2016). However, complete elimination of Category I could create animal health and welfare problems because of the growing prevalence of multidrug-resistant strains of Salmonella and other pathogens that are sensitive only to Category I antimicrobials. It was noted that legislation in the province of Québec could serve as a model for prudent antimicrobial use because it has eliminated Category I antimicrobials for preventive purposes in calf production and requires strong justification for therapeutic use. Research in Belgium also identified risk factors for antimicrobial use on veal farms, notably that antimicrobial use is highly variable between veal operations, even those using the same veterinary clinic, emphasizing the importance of farm-level strategies to reduce antimicrobial use (Bokma et al., 2019). Participants recommended education to promote management practices that maintain calf health, reduce the use of antimicrobials, and largely eliminate Category I antimicrobials.

\section{Use of Education}

Participants saw education as an important tool for motivating change in male dairy calf management (Vas- 
seur et al., 2010). They noted a need to inform producers and veterinarians about the variable health status of male calves leaving dairy farms, the likely effects on subsequent health, and the total length of journey that calves may experience so that this can be considered in calf transport decisions. In particular, education is needed to encourage dairy farmers to consider neonatal care of male calves as critical for their subsequent health and welfare.

Participants reported valuable educational initiatives in Ontario and Québec. These include forums, conferences, and videos coordinated by provincial producer organizations and formal education on calf health through veterinary colleges. Participants also noted that some veterinary clinics have management programs specifically designed to monitor calf health and performance. The panel recommended that educational activities for producers and veterinarians be extended across the country to foster awareness of the variable health status of male calves on dairy farms and provide information on methods to improve calf management, health and welfare. Efforts are also needed to encourage all producers to provide male calves with care that prepares them adequately for transportation.

\section{Euthanasia}

Participants noted that a small but important fraction of male dairy calves sent to auction sell for very little or do not sell at all. In some cases, calves may be sent to auction because farmers are not trained, equipped, or willing to perform euthanasia. Participants recommended the continuation of existing efforts in the dairy sector to develop on-farm euthanasia training materials and protocols and to better understand the barriers to implementation of such protocols.

\section{Marketing Regulations}

In Canada, although the federal government is the primary regulator of animal transport, most animal protection law is made and enforced by the provinces and significant variation exists (Fraser et al., 2018). Participants noted that Ontario is the only province that specifically regulates livestock auctions through its Livestock Community Sales Act, which (1) requires the presence of provincially appointed inspectors when auctions are conducted, and (2) empowers designated veterinarians to require treatment, euthanasia, or prompt local slaughter for compromised animals. In addition, the Ontario dairy industry works with regulators to correct the actions of producers who send compromised animals to auction. After an initial period of adjust- ment, this regulatory framework has seemingly led to substantial reductions in the number of compromised animals sent to auction. However, because the Act applies to auctions but not to calf dealers who buy calves directly from dairy farms, this legislation may have inadvertently resulted in compromised animals being channeled to unregulated markets. Participants recommended that the regulatory approach used for auctions in Ontario be considered by other regions for auctions as well as other forms of livestock sales.

\section{Animal Transport Regulations}

Participants noted that some current industry practices do not comply with the amendments to the federal Health of Animals Regulations (Part XII) on animal transportation (Canadian Food Inspection Agency, 2019). In particular, (1) the new regulations allow calves $8 \mathrm{~d}$ of age or less to be sold directly from farm to farm but not through auction or assembly points, and (2) unweaned calves of any age (i.e., those that cannot be fed exclusively on hay and grain) may be transported for a maximum duration of $12 \mathrm{~h}$.

The amended federal regulations will require significant changes to existing calf transportation practices.

(1) In regions that rely heavily on auctions to sell calves, dairy farmers might keep calves on the farm until $8 \mathrm{~d}$ of age or more but might not have the appropriate housing and skill to maintain calf health during this time. Especially for dairy farms far removed from calf-rearing facilities, a shift to preconditioned calves could provide a lasting solution. Hence, there would be a need for additional housing and increased requirement for skilled labor.

(2) In regions where veal and other calf-rearing facilities do not exist, transporting calves to a grower facility within $12 \mathrm{~h}$ may not be possible. This could lead to calves being euthanized on dairy farms because they cannot be legally transported to rearing facilities. At the least, this would require farms to have training and equipment for euthanasia or access to euthanasia services. Participants noted, however, that farmers (and likely the public) would strongly resist euthanasia of healthy calves; hence, this was viewed as only a stop-gap measure.

(3) In the longer term, the development of local calfrearing facilities (that can be reached within the prescribed $12 \mathrm{~h}$ ) could provide a remedy, but this would require the development of new facilities, which might not be economically justified by the 
current commercial value of male dairy calves. Participants noted that greater use of beef genetics in breeding dairy cows could produce crossbred calves of greater commercial value, which might support such investments.

In summary, participants identified a need for the dairy and calf sectors to work with federal regulators in developing a comprehensive implementation plan to ensure compliance with regulatory amendments without creating unintended negative consequences for the health and welfare of male dairy calves.

\section{General Discussion}

An important knowledge gap was identified regarding the ideal age for transporting dairy calves. Calf age at transport has been considered an important criterion for health and welfare (Knowles, 1995), but there is no scientific consensus on an optimal age for transporting calves. In some studies, stress-related changes in blood constituents were less pronounced and less lasting in younger calves (aged 1-3 wk) compared with those aged 6 mo (Kent and Ewbank, 1983, 1986). Other researchers concluded that healthy calves 5 to $10 \mathrm{~d}$ old showed no detrimental metabolic effects after transport of up to $12 \mathrm{~h}$ (Todd et al., 2000). Such scientific evidence supports participants' views that age alone is not an adequate criterion for fitness for transport, and that more effective assessment tools are needed.

The optimum transportation duration for young calves also requires further clarification. Early studies found minimal differences in calves after 19 (Todd et al., 2000) and $24 \mathrm{~h}$ of transport (Knowles et al., 1997). However, more recent evidence supports a 12 -h maximum for young calves (Bernardini et al., 2012; Fisher et al., 2014). Unfortunately, these studies have primarily evaluated changes in hematological values, so further study involving other measures of health or welfare could help clarify the impacts of transport duration. Second, rest stops for young calves are also mandated in some countries, but appear to provide minimal benefits; for example, with recently weaned beef calves (Marti et al., 2017). Knowles et al. (1997, 1999) also concluded that for journeys up to $24 \mathrm{~h}$, feeding calves mid-transport is of minimal benefit. Ensuring calves are fed and in robust condition before transport may be a better alternative (Marcato et al., 2020).

This expert consultation gave rise to many insights including the wide variation in marketing practices, transport duration and the age and condition of calves when leaving the farm of origin. Additionally, participants raised concerns surrounding biosecurity, calf health, and the use of antimicrobials. Consensus was reached on the need to

(1) use education and other means to inform producers about the variable health status of calves at transport and later,

(2) develop effective means to assess fitness for transport in calves,

(3) minimize biosecurity risks when calves are collected from farms of origin,

(4) ensure that dairy farms are skilled and equipped for euthanasia,

(5) use education to improve calf management and reduce the use of antimicrobials,

(6) explore more uniform regulatory oversight of auctions and other sales channels, and

(7) develop - as a collaboration between industry and federal regulators - a comprehensive implementation plan so that the revised federal animal transport regulations can be met without creating unintended negative effects on male dairy calf health and welfare.

This study was limited by its focus on Canada - a country where dairy farming is widespread but calf raising is concentrated in certain regions. As with any qualitative research, the context of the information-gathering needs to be kept in mind when interpreting the outcomes (Maxwell, 2012). Hence, some of the specific recommendations may apply to other jurisdictions but others may not. For example, the use of blanket antimicrobial treatment in veal calves is prohibited in some European countries, so the recommendation to reduce this practice through education may be inapplicable. However, the method of creating structured discussion among individuals with diverse knowledge - in this case involving dairy farming, transportation, auctions, veterinary medicine, regulation, and calf production-may provide a useful way to identify problems and solutions when comprehensive, multi-disciplinary data collection is not feasible.

\section{ACKNOWLEDGMENTS}

We acknowledge Nathalie Côté (Les Producteurs de Bovins du Québec, Québec, Canada), Mike Draper (Government of Ontario; Ontario, Canada), Ed Friesen (Dairy Farmers of Canada, Ontario, Canada), MarieEve Paradis (Association des Médecins Vétérinaires Praticiens du Québec, Québec, Canada), and Craig Jacklin, Rick Wright, and Larry Witzel (Livestock Markets Association of Canada, Alberta, Canada) for the information they provided during the initial de- 
velopment of this manuscript. We are grateful for the support of the National Farmed Animal Health and Welfare Council and of the BC Ministry of Agriculture who provided funding through the Canadian Agricultural Partnership to conduct this meeting. The authors have not stated any conflicts of interest.

\section{REFERENCES}

Atkinson, D. J., M. A. G. von Keyserlingk, and D. M. Weary. 2017. Benchmarking passive transfer of immunity and growth in dairy calves. J. Dairy Sci. 100:3773-3782. https://doi.org/10.3168/jds .2016-11800.

Bernardini, D., G. Gerardi, A. Peli, L. N. Costa, M. Amadori, and S. Segato. 2012. The effects of different environmental conditions on thermoregulation and clinical and hematological variables in long-distance road-transported calves. J. Anim. Sci. 90:1183-1191. https://doi.org/10.2527/jas.2011-4113.

Bokma, J., R. Boone, P. Deprez, and B. Pardon. 2019. Risk factors for antimicrobial use in veal calves and the association with mortality. J. Dairy Sci. 102:607-618. https://doi.org/10.3168/jds.2018 $-15211$.

Buczinski, S., J. Dubuc, V. Bourgeois, P. Baillargeon, N. Côté, and G. Fecteau. 2020. Validation of serum gamma-glutamyl transferase activity and body weight information for identifying dairy calves that are too young to be transported to auction markets in Canada. J. Dairy Sci. 103:2567-2577. https://doi.org/10.3168/jds.2019 $-17601$.

Canadian Food Inspection Agency. 2019. Regulations Amending the Health of Animals Regulations. Canada Gazette 47-115. Canadian Food Inspection Agency, Ottawa, ON, Canada.

Cave, J. G., A. P. L. Callinan, and W. K. Woonton. 2005. Mortalities in bobby calves associated with long distance transport. Aust. Vet. J. 83:82-84. https://doi.org/10.1111/j.1751-0813.2005.tb12203.x.

European Union. 2005. Council Regulation No 1/2005 on the protection of animals during transport and related operations and amending directives 64/432/EEC and 93/119/EC and regulation (EC) No 1255/97. Off. J L3, 5.1.2005.

Fisher, A. D., B. H. Stevens, M. J. Conley, E. C. Jongman, M. C. Lauber, S. J. Hides, G. A. Anderson, D. M. Duganzich, and P. D. Mansell. 2014. The effects of direct and indirect road transport consignment in combination with feed withdrawal in young dairy calves. J. Dairy Res. 81:297-303. https://doi.org/10.1017/ S0022029914000193.

Fraser, D., K. E. Koralesky, and G. Urton. 2018. Toward a harmonized approach to animal welfare law in Canada. Can. Vet. J. 59:293-302.

González, L. A., K. S. Schwartzkopf-Genswein, M. Bryan, R. Silasi, and F. Brown. 2012. Relationships between transport conditions and welfare outcomes during commercial long haul transport of cattle in North America. J. Anim. Sci. 90:3640-3651. https://doi .org/10.2527/jas.2011-4796.

Kent, J. E., and R. Ewbank. 1983. The effect of road transportation on the blood constituents and behaviour of calves. I. Six months old. Br. Vet. J. 139:228-235. https://doi.org/10.1016/S0007 -1935(17)30489-X

Kent, J. E., and R. Ewbank. 1986. The effect of road transportation on the blood constituents and behaviour of calves. II One to three weeks old. Br. Vet. J. 142:131-140. https://doi.org/10.1016/0007 -1935(86)90088-6.

Knowles, T. G. 1995. Short Communication: A review of post transport mortality among younger calves. Vet. Rec. 137:406-407. https://doi.org/10.1136/vr.137.16.406.

Knowles, T. G., S. N. Brown, J. E. Edwards, A. J. Phillips, and P. D. Warriss. 1999. Effect on young calves of a one-hour feeding stop during a 19-hour road journey. Vet. Rec. 144:687-692. https://doi . org/10.1136/vr.144.25.687.
Knowles, T. G., P. D. Warriss, S. N. Brown, J. E. Edwards, P. E. Watkins, and A. J. Phillips. 1997. Effects on calves less than one month old of feeding or not feeding them during road transport of up to 24 hours. Vet. Rec. 140:116-124. https://doi.org/10.1136/ vr.140.5.116.

Krueger, R. A., and M. A. Casey. 2000. Focus Groups: A Practical Guide for Applied Research. Sage Publications, Thousand Oaks, CA.

Lava, M., G. Schüpbach-Regula, A. Steiner, and M. Meylan. 2016. Antimicrobial drug use and risk factors associated with treatment incidence and mortality in Swiss veal calves reared under improved welfare conditions. Prev. Vet. Med. 126:121-130. https://doi.org/ 10.1016/j.prevetmed.2016.02.002.

Marcato, F., H. van den Brand, B. Kemp, B. Engel, M. WolthuisFillerup, and K. van Reenen. 2020. Effects of pretransport diet, transport duration, and type of vehicle on physiological status of young veal calves. J. Dairy Sci. 103:3505-3520. https://doi.org/10 $.3168 /$ jds.2019-17445.

Marquou, S., L. Blouin, H. Djakite, R. Laplante, and S. Buczinski. 2019. Health parameters and their association with price in young calves sold at auction for veal operations in Québec, Canada. J. Dairy Sci. 102:6454-6465. https://doi.org/10.3168/jds.2018-16051.

Marti, S., R. E. Wilde, D. Moya, C. E. M. Heuston, F. Brown, and K. S. Schwartzkopf-Genswein. 2017. Effect of rest stop duration during long-distance transport on welfare indicators in recently weaned beef calves. J. Anim. Sci. 95:636-644. https://doi.org/10 $.2527 /$ jas2016.0739.

Maxwell, J. A. 2012. A Realist Approach for Qualitative Research. Sage Publications, Thousand Oaks, California.

Medrano-Galarza, C., S. J. LeBlanc, A. Jones-Bitton, T. J. DeVries, J. Rushen, A. M. de Passillé, M. I. Endres, and D. B. Haley. 2018. Associations between management practices and within-pen prevalence of calf diarrhea and respiratory disease on dairy farms using automated milk feeders. J. Dairy Sci. 101:2293-2308. https: //doi.org/10.3168/jds.2017-13733.

National Animal Welfare Advisory Committee. 2018. Code of Welfare: Transport within New Zealand. https://www.mpi.govt.nz/ dmsdocument/1407/direct.

National Farmed Animal Health and Welfare Council. 2019. Advancing Animal Health and Welfare in Canada. https://www .ahwcouncil.ca/.

Pempek, J., D. Trearchis, M. Masterson, G. Habing, and K. Proudfoot. 2017. Veal calf health on the day of arrival at growers in Ohio. J. Anim. Sci. 95:3863-3872. https://doi.org/10.2527/jas2017 .1642 .

Renaud, D. L., T. F. Duffield, S. J. LeBlanc, D. B. Haley, and D. F. Kelton. 2017. Management practices for male calves on Canadian dairy farms. J. Dairy Sci. 100:6862-6871. https://doi.org/10.3168/ jds.2017-12750.

Renaud, D. L., T. F. Duffield, S. J. LeBlanc, D. B. Haley, and D. F. Kelton. 2018a. Clinical and metabolic indicators associated with early mortality at a milk-fed veal facility: A prospective case-control study. J. Dairy Sci. 101:2669-2678. https://doi.org/10.3168/ jds.2017-14042.

Renaud, D. L., D. F. Kelton, S. J. LeBlanc, D. B. Haley, and T. F. Duffield. 2018b. Calf management risk factors on dairy farms associated with male calf mortality on veal farms. J. Dairy Sci. 101:1785-1794. https://doi.org/10.3168/jds.2017-13578.

Renaud, D. L., M. W. Overton, D. F. Kelton, S. J. Leblanc, K. C. Dhuyvetter, and T. F. Duffield. 2018c. Effect of health status evaluated at arrival on growth in milk-fed veal calves: A prospective single cohort study. J. Dairy Sci. 101:10383-10390. https://doi .org/10.3168/jds.2018-14960.

Scott, K., D. F. Kelton, T. F. Duffield, and D. L. Renaud. 2020. Short communication: Risk factors identified at arrival associated with average daily gain at a grain-fed veal facility: A prospective single cohort study. J. Dairy Sci. 103:858-863. https://doi.org/10.3168/ jds.2019-17220.

Stojkov, J., G. Bowers, M. Draper, T. Duffield, P. Duivenvoorden, M. Groleau, D. Haupstein, R. Peters, J. Pritchard, C. Radom, N. Sil- 
lett, W. Skippon, H. Trépanier, and D. Fraser. 2018. Hot topic : Management of cull dairy cows - Consensus of an expert consultation in Canada. J. Dairy Sci. 101:11170-11174. https://doi.org/10 .3168/jds.2018-14919.

Sumner, C. L., and M. A. G. von Keyserlingk. 2018. Canadian dairy cattle veterinarian perspectives on calf welfare. J. Dairy Sci. 101:10303-10316. https://doi.org/10.3168/jds.2018-14859.

Todd, S. E., D. J. Mellor, K. J. Stafford, N. G. Gregory, R. A. Bruce, and R. N. Ward. 2000. Effects of food withdrawal and transport on 5- to 10-day-old calves. Res. Vet. Sci. 68:125-134. https://doi .org/10.1053/rvsc.1999.0345.

Vasseur, E., J. Rushen, A. M. de Passillé, D. Lefebvre, and D. Pellerin. 2010. An advisory tool to improve management practices affecting calf and heifer welfare on dairy farms. J. Dairy Sci. 93:4414-4426. https://doi.org/10.3168/jds.2009-2586.
Wells, S. J., L. P. Garber, and G. W. Hill. 1997. Health status of preweaned dairy heifers in the United States. Prev. Vet. Med. 29:185199. https://doi.org/10.1016/S0167-5877(96)01078-1.

Winder, C. B., D. F. Kelton, and T. F. Duffield. 2016. Mortality risk factors for calves entering a multi-location white veal farm in Ontario, Canada. J. Dairy Sci. 99:10174-10181. https://doi.org/10 $.3168 /$ jds.2016-11345.

\section{ORCIDS}

Devon J. Wilson (1) https://orcid.org/0000-0001-8027-7998

David L. Renaud ๑ https://orcid.org/0000-0002-3439-3987 